University of Nebraska - Lincoln

DigitalCommons@University of Nebraska - Lincoln

USDA National Wildlife Research Center - Staff Publications
U.S. Department of Agriculture: Animal and Plant Health Inspection Service

2011

\title{
Active Use of Coyotes (Canis latrans) To Detect Bovine Tuberculosis In Northeastern Michigan, USA
}

\author{
Are R. Berentsen \\ USDA APHIS WS National Wildlife Research Center, Fort Collins, Colorado \\ Michael R. Dunbar \\ Shylo R. Johnson \\ USDA National Wildlife Research Center, Fort Collins, CO \\ S. Robbe-Austerman \\ L. Martinez
}

See next page for additional authors

Follow this and additional works at: https://digitalcommons.unl.edu/icwdm_usdanwrc

Part of the Environmental Sciences Commons, and the Life Sciences Commons

Berentsen, Are R.; Dunbar, Michael R.; Johnson, Shylo R.; Robbe-Austerman, S.; Martinez, L.; and Jones, R. L., "Active Use of Coyotes (Canis latrans) To Detect Bovine Tuberculosis In Northeastern Michigan, USA" (2011). USDA National Wildlife Research Center - Staff Publications. 1007.

https://digitalcommons.unl.edu/icwdm_usdanwrc/1007

This Article is brought to you for free and open access by the U.S. Department of Agriculture: Animal and Plant Health Inspection Service at DigitalCommons@University of Nebraska - Lincoln. It has been accepted for inclusion in USDA National Wildlife Research Center - Staff Publications by an authorized administrator of DigitalCommons@University of Nebraska - Lincoln. 


\section{Authors}

Are R. Berentsen, Michael R. Dunbar, Shylo R. Johnson, S. Robbe-Austerman, L. Martinez, and R. L. Jones 


\title{
Active use of coyotes (Canis latrans) to detect Bovine Tuberculosis in northeastern Michigan, USA
}

\author{
A.R. Berentsen ${ }^{\text {a, }}$, M.R. Dunbar ${ }^{\text {a }}$, S.R. Johnson ${ }^{\text {a }}$, S. Robbe-Austerman ${ }^{\text {b }}$, L. Martinez ${ }^{\text {c }}$, R.L. Jones ${ }^{\mathrm{c}}$ \\ ${ }^{a}$ USDA/APHIS/WS/National Wildife Research Center 4101 LaPorte Ave. Ft. Collins, CO 80521, USA \\ ${ }^{\mathrm{b}}$ USDA/APHIS/VS/National Veterinary Services Laboratories, Ames, IA 50010, USA \\ ${ }^{\mathrm{c}}$ Department of Microbiology, Immunology and Pathology, Colorado State University, Ft. Collins, CO 80523-1682, USA
}

\section{A R T I C L E I N F O}

\section{Keywords:}

Bovine tuberculosis

Canis latrans

Coyote

Michigan

Mycobacterium bovis

Sentinel

\begin{abstract}
A B S T R A C T
Bovine tuberculosis (bTB) is endemic in white-tailed deer (Odocoileus virginianus) in northeastern Michigan, USA, and research suggests transmission to cattle. Prevalence of the disease in deer is estimated at $1.8 \%$, but as prevalence decreases the difficulty of detection increases. Research suggests coyotes (Canis latrans) have a higher prevalence of bTB in Michigan than deer and sampling coyotes may be a more efficient surveillance tool to detect presence or spread of the disease. Coyotes possess suitable ecological characteristics to serve as a sentinel species, assuming transmission between coyotes is not significant. The question of whether free-ranging coyotes shed Mycobacterium bovis, the causative agent of bTB, has not been previously addressed. We actively used coyotes as a sentinel to detect bTB in infected and uninfected counties in Michigan's Northeastern Lower Peninsula. We determined whether bTB infection was present through bacteriologic culture of lymph nodes and tissues containing lesions and cultured oral/ nasal swabs and feces to establish shedding. Seventeen of 171 coyotes were M. bovis culture positive, one of which was from a previously uninfected county. All oral, nasal secretions and feces were culture negative suggesting minimal, if any, shedding of M. bovis. Thus, infection of coyotes is likely to occur through ingestion of infected deer carcasses and not from interaction with conspecifics. These findings support previous research suggesting that coyotes are useful sentinels for bTB. The use of coyotes as a sentinel, may allow wildlife managers to detect the spread of bTB into naïve counties. With earlier detection managers may be able to take proactive surveillance measures to detect the disease in deer and reduce the potential risk to domestic livestock and captive deer herds. Published by Elsevier B.V.
\end{abstract}

\section{Introduction}

Bovine tuberculosis (bTB), a contagious disease caused by the bacterium Mycobacterium bovis, is capable of infecting wildlife, livestock and humans. In the United States (US) the disease has historically been restricted to domestic cattle and captive cervids, with cases in freeranging wildlife rarely reported. Internationally, bTB in wildlife is well documented. Cases of bTB have been

\footnotetext{
* Corresponding author. Tel.: +1 970266 6221; fax: +1 9702666138 E-mail address: Are.R.Berentsen@aphis.usda.gov (A.R. Berentsen).
}

reported in elk (Cervus elaphus manitobensis) and bison (Bison bison athabascae) in Canada (Nishi et al., 2006), brushtail possums (Trichosurus vulpecula) in New Zealand (Coleman, 1988) and the Eurasian badger (Meles meles) in the United Kingdom (Cheeseman et al., 1988). In Southern Africa bTB is found in Kafue lechwe (Kobus leche kafuensis) (Munyeme et al., 2009) and Cape buffalo (Syncerus caffer) (DeVos et al., 2001). Only in recent years has it been documented in several wildlife species in the US, including coyotes (Canis latrans), raccoons (Procyon lotor) and red fox (Vulpes ulpes), among others (Bruning-Fann et al., 2001). However, it is unknown whether bTB transmission within or among these species occurs. 
In the 1994 hunting season a hunter-killed white-tailed deer (Odocoileus virginianus) in Michigan's Northeastern Lower Peninsula (NELP) was found to have lesions consistent with bTB and by 1998 the disease was also found in Michigan cattle (Schmitt et al., 2002). This resulted in revocation of Michigan's Accredited TB-Free status by the US Department of Agriculture, restriction of inter and intrastate movement of cattle and the establishment of a modified accredited zone (MAZ) to contain the disease. Genotyping of $M$. bovis strains from Michigan deer and cattle suggests transmission between the two species (Milian-Suazo et al., 2008). This finding represented the first known case of an endemic cervid reservoir of bTB and resulting spread to livestock in North America (O'Brien et al., 2002). Previous cases of bTB in captive North American cervids were associated with outbreaks in domestic livestock, but once the livestock reservoir was eliminated the disease did not persist in wildlife (Essey and Vantiem, 1995).

In response to the bTB outbreak in white-tailed deer and the concomitant threat of transmission to livestock, Michigan Department of Natural Resources (MDNR) engaged in reductions in the deer population, reducing deer congregations by restrictions on supplemental feeding and using bait piles for hunting (Schmitt et al., 2006). Subsequently, the apparent prevalence of bTB in deer dropped from a high of $4.9 \%$ in 1995 to a low $1.2 \%$ in 2006 (O'Brien, 2008). Since 2006 the apparent prevalence has remained relatively stable near 2.0\% (O'Brien et al., 2011).

While these results appear encouraging, infection of domestic livestock and captive deer farms continue, suggesting current strategies may not be sufficient to achieve eradication of the disease. Bovine tuberculosis surveillance relies on testing of hunter-killed deer submitted at hunter check stations. Research indicates only $56 \%$ of resident hunters in the bTB outbreak area of northeastern Michigan bring harvested deer to check stations (Dorn and Mertig, 2005). This may not be a cause for concern unless bias exists in the samples submitted. For example, the number of hunter-killed positive deer that are either left in the field or buried without being reported may add a degree of uncertainty to prevalence estimates.

Proactive measures must be undertaken with respect to disease surveillance in the wildlife reservoir. Early detection in the primary wildlife reservoir can help wildlife and livestock managers focus on strategies to reduce the potential transmission to livestock. However, detection of disease becomes increasingly difficult as prevalence in the primary reservoir declines. Thus, alternative strategies for the detection of disease agents must be considered. One such strategy is the use of wildlife sentinels. Sentinels have been proposed for a variety of zoonotic diseases, including West Nile Virus (Eidson et al., 2001) and other arboviruses (Trainer, 1970), Lyme disease (Lindenmayer et al., 1991) and bTB (Nugent et al., 2002). They can be an efficient tool in early detection of disease outbreaks, especially when the primary species of interest are difficult to sample directly or the disease occurs at a low prevalence. In order for an animal to be considered an effective sentinel it is desirable that the species have a known limited home range, not be adversely affected by disease (Trainer, 1970) or shed, either in excrement or oral/nasal secretions, the causative agent. It is also advantageous if the sentinel is easier to sample or functions as a bio-accumulator so that detection probabilities in the sentinel are higher than for the reservoir. Furthermore, disease in the sentinel should not be able to persist in the absence of the species being surveilled. Atwood et al. (2007) suggested coyotes possess several of the ecological characteristics suitable for a sentinel species. In Michigan, VerCauteren et al. (2008) sampled $97 \%$ fewer individuals and increased the likelihood of bTB detection by $40 \%$ by sampling coyotes rather than deer. However, in the Atwood et al. (2007) study, a significant characteristic of a sentinel species was not addressed: shedding of $M$. bovis by the potential sentinel species. The social behavior of coyotes is well documented (Bekoff and Gese, 2003 and references therein), but because of correlated movement behavior in coyotes, shedding of $M$. bovis by individual coyotes within a pack could result in transmission between individuals. Such transmission could be confounding, making it unclear whether infection occurred through interaction with conspecifics or through other sources, such as ingestion of infected deer carcasses. Shedding of $M$. bovis by coyotes could reduce their usefulness as a sentinel.

The objectives of this study were to: (1) use coyotes as a sentinel for presence of $M$. bovis in bTB infected and uninfected counties in and around Michigan's MAZ, (2) establish whether coyotes with tissue cultures positive for bTB infection actively shed $M$. bovis from feces or body fluids, and (3) estimate prevalence of bTB in coyotes in infected counties and compare prevalence rates with previous research.

\section{Materials and methods}

\subsection{Study sites}

Sample collection was performed on public land in six counties in the NELP (Fig. 1) from October 2006 to July 2009. Dominant habitat types consist of deciduous forest (29.8\%), woody wetlands (19.3\%) and evergreen forest (13.2\%). Cultivated crops and pasture land occupied 4.9\% and $2.2 \%$, respectively (USDA, 2007). Two counties fell within the core bTB area, three were outside the core area, but completely or partially within the MAZ, and one was completely outside the MAZ. Three counties (Alcona, Alpena and Iosco) had a history of bTB in wildlife and/or domestic cattle and three counties (Cheboygan, Kalkaska and Ogemaw Counties) were uninfected. To distribute sampling, each county was divided into four or five main sampling units. Each main unit was then divided into three, four or five evenly sized sections. One to two sections per main unit were randomly selected for the primary capture sites. A prioritized alternate list for capture sites was generated in the event the primary site was unsuitable for sampling. Additionally, the naïve counties had $7.5 \mathrm{~km}$ buffer zone excluded from sampling along borders shared with counties having a history of infected wildlife or domestic animals. Maps and coyote locations were plotted using ArcGIS v9.2 (ESRI, Redlands, CA, USA) software. 


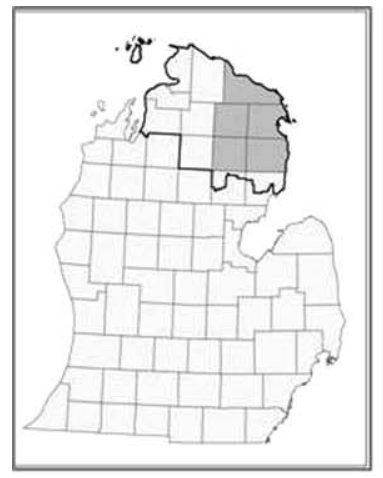

\section{Legend}
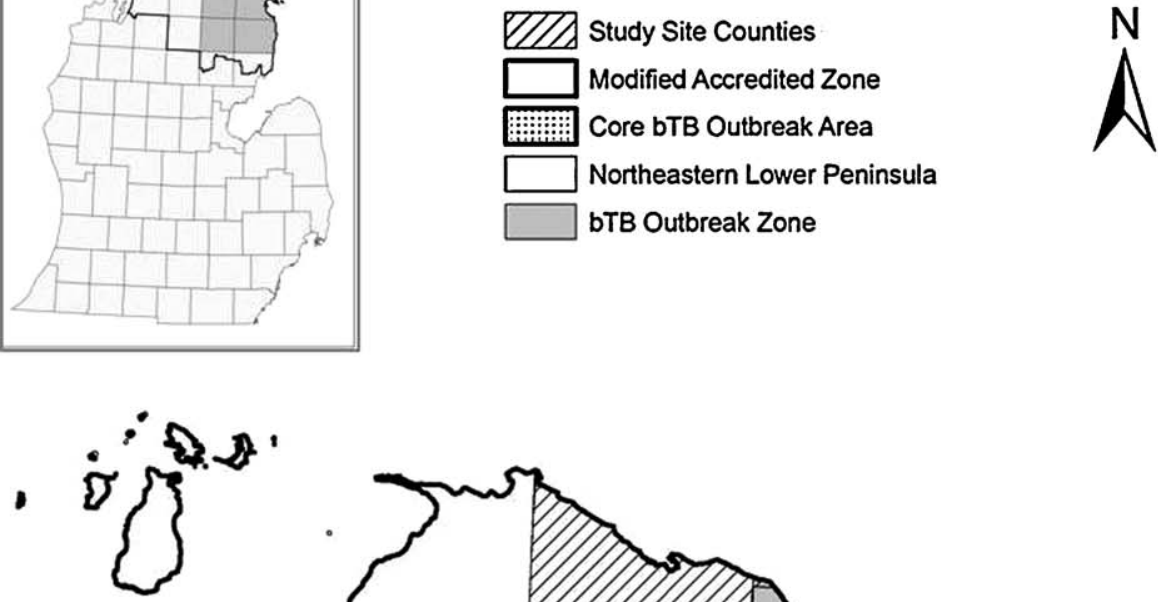

.
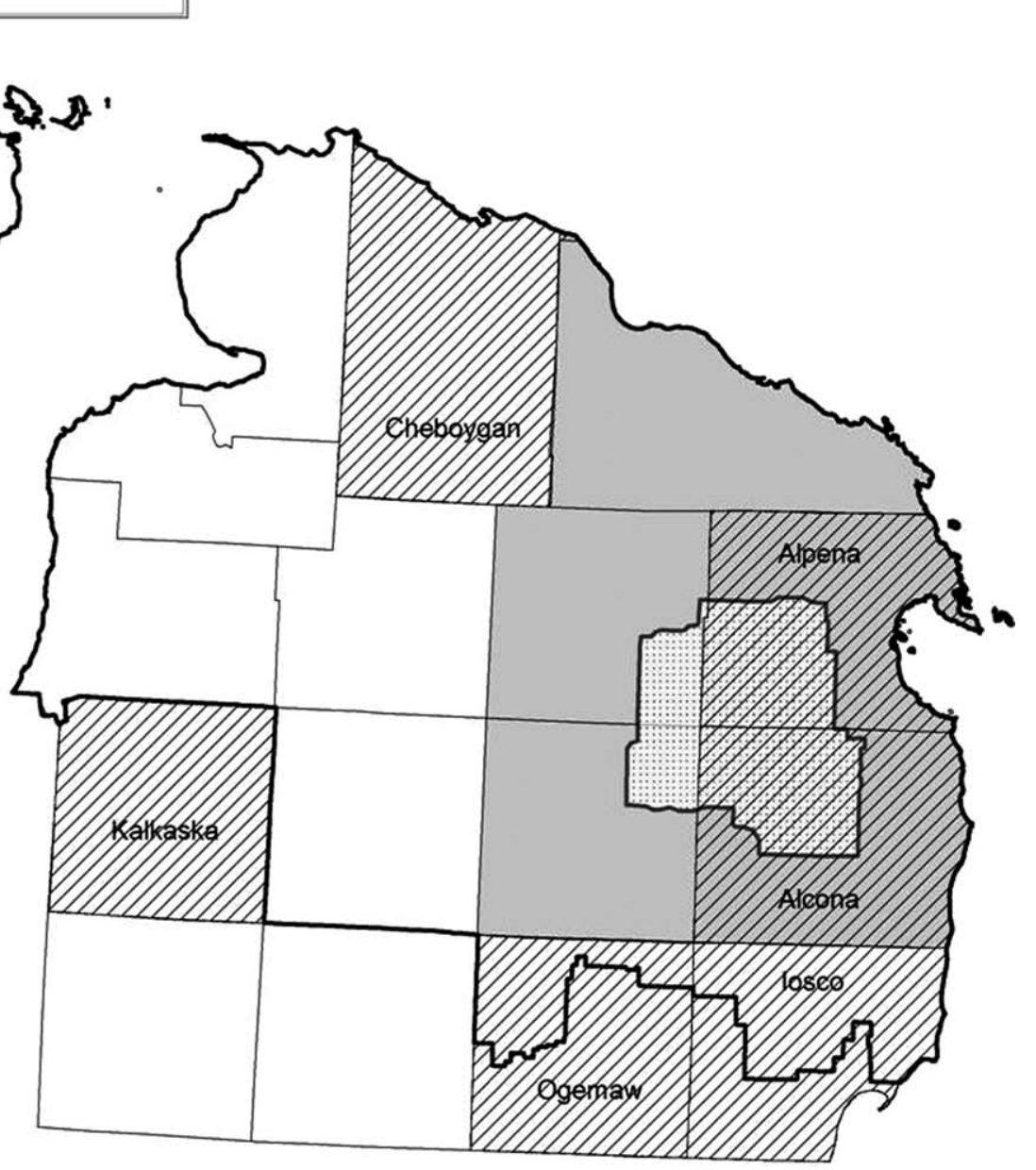

Fig. 1. Michigan's Northeastern Lower Peninsula, the modified accredited zone, bTB outbreak zone, bTB core outbreak area and study locations.

\subsection{Animal capture and sample collection}

Coyotes were live-trapped using cable-restraining devices and \#3 Victor Soft Catch ${ }^{\circledR}$ (Woodstream Corp., Lititz, PA, USA) traps equipped with a Paws-I-Trip ${ }^{\mathrm{TM}}(\mathrm{M}-\mathrm{Y}$ Enterprises, Homer City, PA, USA) pan-tension device to reduce non-target captures. Coyotes were euthanized via a 0.22 caliber gunshot through the brain and necropsies were performed immediately in the field. Samples of lymph nodes (parotid, mandibular, retropharyngeal, bronchial, mediastinal and mesenteric) were obtained along with samples of any tissues that appeared to contain tuberculous lesions. Samples were divided and pooled by region (head, thorax and abdomen). Half the samples from each region were frozen, the other half stored in $10 \%$ buffered formalin. Two oral and two nasal swabs were obtained as well as fecal samples, when available. A single canine tooth was extracted for aging. Teeth were heat inactivated in a water bath at $75^{\circ} \mathrm{C}$ for $60 \mathrm{~min}$ prior to shipment to prevent potential disease transmission to laboratory technicians or other staff. Frozen tissue samples were packed in dry ice or cooling packs and shipped overnight to USDA/APHIS/VS National Veterinary Services Laboratories (NVSL) in Ames, Iowa where they were frozen 
Table 1

Culture results for coyotes in Michigan's NELP.

\begin{tabular}{|c|c|c|c|c|c|c|}
\hline County & Hist+/Cult+ & Hist-/Cult + & Hist+/Cult- & Hist-/Cult- & Other acid fast organism & Hist-Cult contaminated \\
\hline Alcona & 4 & 5 & 2 & 19 & 0 & 0 \\
\hline Alpena & 3 & 1 & 0 & 25 & 2 & 1 \\
\hline Cheboygan & 0 & 1 & 0 & 17 & 1 & 1 \\
\hline Iosco & 1 & 2 & 2 & 21 & 2 & 2 \\
\hline Kalkaska & 0 & 0 & 0 & 30 & 1 & 0 \\
\hline Ogemaw & 0 & 0 & 0 & 29 & 3 & 0 \\
\hline Total & 8 & 9 & 4 & 141 & 9 & 4 \\
\hline
\end{tabular}

at $-20^{\circ} \mathrm{C}$ until culture. A fecal sample and the oral/nasal swabs were similarly packed and shipped overnight to the Department of Microbiology, Immunology and Pathology laboratory at Colorado State University where they were similarly stored.

Teeth were shipped to USDA/APHIS/WS/National Wildlife Research Center in Ft. Collins, Colorado and aged by cementum annuli analysis (Johnston et al., 1999). In cases where a definitive age could not be established the average was used to represent the age (i.e., 3-4 years represented as 3.5 years).

Capture and handling of coyotes was approved by the Institutional Animal Care and Use Committee under QA1355 at USDA/APHIS/WS/National Wildlife Research Center in Ft. Collins, CO, USA.

\subsection{Tissue histology, culture and analysis}

Routine histological examinations were performed at NVSL. For culture, tissues were decontaminated using $2 \%$ sodium hydroxide and inoculated into BACTEC 12B media and MGIT 960 media following manufacturer's instructions with additional erythromycin to control contamination (Hines et al., 2006). Positive cultures were confirmed as Mycobacterium tuberculosis complex and Mycobacterium bovis by nucleic acid probes and spoligotyping, respectively. Samples were considered negative if at least one of the two media did not signal positive for the six-week incubation period, and no Mycobacterium tuberculosis complex organisms were recovered. If all media signaled positive and there were no acid fast organisms visible upon staining, the sample was considered contaminated. Samples that grew acid fast organisms and were negative for Mycobacterium tuberculosis complex using the nucleic acid probe were reported out as acid fast organisms isolated, not Mycobacterium tuberculosis complex. Cases in which samples cultured positive for $M$. tuberculosis complex, but contamination precluded speciation were assumed to be positive for $M$. bovis based on the low likelihood of a coyote being positive for $M$. tuberculosis, typically found in humans. Only coyotes that were confirmed using bacteriologic culture were considered positive.

Swabs and fecal samples from all animals positive on tissue culture were cultured at the Department of Microbiology, Immunology and Pathology laboratory at Colorado State University using techniques adapted from Crossley et al. (2005). Two grams of fecal sample from each animal were transferred into $35.0 \mathrm{ml}$ of water in $50.0 \mathrm{ml}$ conical polypropylene tubes. The oral and nasal swabs from each animal were combined and the swab tips were broken off into $35.0 \mathrm{ml}$ water in $50.0 \mathrm{ml}$ tubes. The positive control tube contained $35.0 \mathrm{ml}$ water inoculated with $1.0 \mu$ loop of Mycobacterium bovis. The samples were vortexed multiple times to create homogeneous suspensions, and then allowed to settle for $30 \mathrm{~min}$ at room temperature. Using sterile, disposable transfer pipettes, $5.0 \mathrm{ml}$ of each sample was transferred from the top portion of the tube to a second $50.0 \mathrm{ml}$ tube containing $25.0 \mathrm{ml}$ of $0.9 \%$ hexadecylpyridinium chloride in brain heart infusion broth and incubated at $37{ }^{\circ} \mathrm{C}$ for $18-24 \mathrm{~h}$ for decontamination and germination. The samples were centrifuged at $900 \times \mathrm{g}$ for $30 \mathrm{~min}$, and the supernatant was discarded. The pellets were re-suspended by adding $1.0 \mathrm{ml}$ of antibiotic solution that contained $5.0 \mathrm{mg} / \mathrm{ml}$ amphotericin $\mathrm{B}$, $10.0 \mathrm{mg} / \mathrm{ml}$ nalidixic acid and $10.0 \mathrm{mg} / \mathrm{ml}$ vancomycin in $50 \%$ brain heart infusion broth. After briefly vortexing, samples were incubated at $37^{\circ} \mathrm{C}$ for $18-24 \mathrm{~h}$. Two $7 \mathrm{H} 10$ agar plates containing sodium pyruvate were inoculated with $200.0 \mu \mathrm{l}$ of each sample and incubated at $37^{\circ} \mathrm{C}$. Plates were checked for contamination at day three, and then weekly for growth for eight weeks.

Table 2

Number of coyotes cultured positive for M. bovis in Michigan's NELP.

\begin{tabular}{|c|c|c|c|c|}
\hline \multirow[t]{2}{*}{ County } & \multirow[t]{2}{*}{ \# Positive (\# usable samples) } & \multirow[t]{2}{*}{ \% Prevalence } & \multicolumn{2}{|c|}{ 95\% Confidence limits } \\
\hline & & & Lower & Upper \\
\hline Alcona stratified & $9(30)$ & $30.00 \%$ & $13.60 \%$ & $46.40 \%$ \\
\hline Alcona clustered & $6(24)$ & $25.00 \%$ & $7.68 \%$ & $42.32 \%$ \\
\hline Alpena & $4(31)$ & $12.90 \%$ & $1.10 \%$ & $24.70 \%$ \\
\hline Cheboygan & 1 (19) & $5.26 \%$ & $0.00 \%$ & $15.30 \%$ \\
\hline Iosco & $3(28)^{a}$ & $10.71 \%$ & $0.00 \%$ & $22.17 \%$ \\
\hline Ogemaw & $0(32)$ & $0.00 \%$ & $0.00 \%$ & $0.00 \%$ \\
\hline Kalkaska & $0(31)$ & $0.00 \%$ & $0.00 \%$ & $0.00 \%$ \\
\hline
\end{tabular}

\footnotetext{
${ }^{\mathrm{a}}$ Includes one sample that cultured M. tuberculosis complex and was assumed to be $M$. bovis.
} 
Table 3

Mean age by year of coyotes sampled in bTB positive counties, Northeastern Michigan, USA, 2007-2008.

\begin{tabular}{lllll}
\hline Year & $n^{\text {a }}$ & Mean age (years) & \multicolumn{2}{l}{$\begin{array}{l}\text { 95\% Confidence } \\
\text { intervals }\end{array}$} \\
\cline { 3 - 5 } & & & Lower & Upper \\
\hline 2007 & 43 & 5.20 & 4.43 & 5.97 \\
2008 & 61 & 4.12 & 3.55 & 4.70 \\
\hline
\end{tabular}

${ }^{a}$ Number of coyotes for which age data was available.

\section{Statistical analysis}

We hypothesized that bTB status would be related to coyote age and sex. Year of capture was included in analysis to account for potential variability between years. Chi-square analysis was used to compare county prevalence as well as bTB status by capture year and sex using the FREQ procedure in SAS v. 9.1 (SAS Institute, Cary, North Carolina). Age and status between years was compared using $t$-tests. Statistical significance is given at $\alpha<0.05$.

\section{Results}

\subsection{Culture results}

Tissue samples, oral/nasal swabs and fecal samples from 175 coyotes were submitted for culture. Only one coyote showed an advanced stage of disease, indicated by extensive lesions in the lungs and mesenteric lymph nodes. Overall, histological lesions found in the coyotes were consistent with previous reports which are described in detail in VerCauteren et al. (2008). Four tissue samples negative by histopathologic examination were contaminated upon culture, resulting in 171 usable results. Table 1 displays the histology and culture results for all 175 coyotes. Seventeen (nine male, eight female) samples cultured positive for $M$. bovis. Spoligotype patterns from all tuberculosis complex nucleic acid positive isolates recovered from coyote tissues were consistent with $M$. bovis and matched the previously reported spoligotype pattern from wild white-tailed deer in Michigan. Of these $17 \mathrm{M}$. bovis culture positive coyotes, 16 came from previously infected counties and one came from an uninfected county. All oral/ nasal swabs and fecal samples from these 17 coyotes were culture negative for $M$. bovis.

\section{2. bTB prevalence estimate}

Coyotes positive for bTB were found in four of six study counties: Alcona, Alpena, Cheboygan and Iosco. From these four counties, 108 usable samples were obtained: 52 males (nine positive), 55 females (eight positive) and one (negative) whose sex was not recorded. Bovine tuberculosis prevalence ranged from $5.26 \%$ to $30.00 \%$ (Table 2 ). Alcona County showed the highest prevalence at $30.00 \%$, which did not differ from the $38.98 \%$ prevalence reported by VerCauteren et al. (2008) (Fisher's exact test, $p=0.49$ ). Prevalence in Alpena county was $12.90 \%$, representing a decrease from 45.45\% reported in VerCauteren et al. (2008) (Fisher's exact test, $p=0.01$ ). Previous prevalence esti- mates for Iosco county are not available for comparison. The discovery of a bTB positive coyote in Cheboygan county represents the first reported case of bTB from any species in that county.

\subsection{Statistical analysis}

The mean age of coyotes was 4.6 years (range 1 to $>10$, $\mathrm{SD}=2.40, n=104,4$ not aged). Coyotes caught in 2008 were younger $(\bar{x}=4.12$ years) than those caught in 2007 $(\bar{x}=5.20$ years) $(t=2.30, p=0.02, \mathrm{df}=102, n=104)$ (Table $3)$. Prevalence did not vary with age $(t=-0.24$, $\mathrm{df}=102$, $n=104, p=0.81)$. The number of positive coyotes did not differ between years $\left(\chi^{2}=1.24, \mathrm{df}=1, n=108, p=0.26\right)$ or by $\operatorname{sex}\left(\chi^{2}=0.15, \mathrm{df}=1, n=107, p=0.70\right)$.

\section{Discussion}

Based on currently available culture methods coyotes were not found to shed $M$. bovis from oral and nasal secretion or feces. No evidence of oral or airway infection was detected as a possible source of aerosol transmission. Given that scavenged deer make up a large part of coyote diets in Michigan (Ozoga and Harger, 1966) and the predominance of lesions in the mesenteric lymph nodes, we believe infection most likely occurs from outside sources such as feeding on infected deer carcasses. Little information is available in the literature on intraspecific scavenging by coyotes as a potential source of infection. Trace amounts of coyote hair have been found in coyote feces (Andrews and Boggess, 2001), but whether this resulted from scavenging or grooming is unknown. Aggression between coyotes can result in mortality, but these activities are typically the result of competition for resources and not predation.

It is possible that currently available culture techniques are not sufficiently sensitive to detect all shedding. In addition, the required dose to produce bTB infection in coyotes or what they would encounter in field settings remains unknown. It appears that the doses coyotes received in this field study were sufficient to cause infection, but not detectable shedding. Johnson et al. (2008) inoculated captive coyotes with $1.0 \times 10^{5} \mathrm{CFU} / \mathrm{ml}$ of $M$. bovis with no resulting infection and no evidence of bacterial shedding in feces or oral/nasal swabs 10-129 days post-inoculation. However, in the Johnson et al. (2008) study it remains unclear whether bacteria were excreted in feces or urine prior to commencement of sample collection.

Because older coyotes have a longer history of potential disease exposure, we expected to see a difference in age between positive and negative coyotes. However, age was not a significant factor in predicting bTB status in coyotes, nor was sex. This suggests that targeting coyotes based on sex or age would not be necessary for effective surveillance. The statistical difference in coyote age between capture years is likely driven by a larger number of oneyear-old coyotes caught in 2008 than in 2007.

The discovery of a bTB positive coyote from Cheboygan county represents the first case of bTB in any species from this county. We are unable to determine if the coyote was 
infected in Cheboygan or if it was infected in a neighboring county and then dispersed. For example, the Presque Isle county boundary is approximately $15 \mathrm{~km}$ to the east and an infected hunter-killed white tailed deer was reported from there in 2008. As the location of that deer has not been disclosed, it is difficult to estimate the most recent possible source of infection. Other potential sources of infection include cervid or cattle farms, but Presque Isle County has not reported a positive bTB cervid or cattle farm since 1997 and 2000, respectively (S. Schmitt, MDNR, personal communication). In addition, these farms are approximately $30-40 \mathrm{~km}$ away from our capture site. Long distance dispersal of coyotes is not unheard of. Kolbe and Squires (2004) reported a coyote dispersed over $300 \mathrm{~km}$ from Montana to Canada, and Carbyn and Paquet (1985) documented movements of over $500 \mathrm{~km}$. However, we believe the likelihood of a single coyote ingesting a bTB infected deer, and subsequently being captured up to $40 \mathrm{~km}$ away is low. And while a single positive coyote does not definitively demonstrate bTB has moved into the county permanently, the fact that Cheboygan County shares a border with four previously or currently infected counties, the possibility should not be ignored. At the very least, this finding could provide incentive for livestock owners to maintain vigilance with respect to TB testing and biosecurity while additional information is gathered.

During the 2007 hunting season two white-tailed deer positive for bTB were identified in Iosco County. These were found approximately 21 and $40 \mathrm{~km}$ south of the outbreak zone, and represent the first cases of bTB in that county since 1999 (S. Schmitt, MDNR, personal communication). The three bTB positive coyotes from Iosco County were collected approximately one year after the discovery of the positive deer. Two coyotes were sampled approximately $3.5 \mathrm{~km}$ from the southernmost deer, a distance that is within the average coyote home range size described by Atwood et al. (2007). The third coyote was caught approximately $48 \mathrm{~km}$ south of the outbreak zone, and $10 \mathrm{~km}$ south of the MAZ. Whether this coyote dispersed from the outbreak zone remains unknown. These results suggest that despite eradication efforts, bTB appears to be spreading. Given that one bTB positive coyote was found south of the MAZ it may be prudent to increase surveillance in deer in the southern portion of Iosco county.

The prevalence difference between this study and previous work in Alpena county is largely the effect of differing sampling methods. VerCauteren et al. (2008) reported a prevalence of $45.5 \%$ in Alpena county. However, sampling was clustered within that portion of Alpena county included in the bTB core area, thus the prevalence should not be interpreted as county-wide. We stratified sampling efforts throughout the county and estimated bTB prevalence in coyotes to be $12.9 \%$. This difference in prevalence does not suggest that bTB prevalence in Alpena county has dropped in recent years merely that the overall prevalence is lower than that found within the portion of the county that includes the outbreak zone. Odds ratio analysis suggests clustered sampling resulted in a 5.63 (95\% CI $=1.47,21.57)$ greater chance of capturing an infected animal than stratifying sample collection throughout Alpena county (Fisher's exact test, $p=0.01$ ).
In Alcona county large portions of private land limited the sites suitable for trapping. As a result, $80 \%$ coyotes were captured within a seven $\mathrm{km}$ radius south of the outbreak zone, representing a sampling scheme similar to that performed by VerCauteren et al. (2008) and comparable prevalence estimates. Given the similarity in sampling techniques and proximity to the bTB outbreak zone between the two studies in Alcona county, this result is not surprising. It is possible that when numerous bTB positive coyotes are found in close proximity they may become infected by feeding on the same infected deer carcass(es). Nonetheless, a localized prevalence must not be construed to represent the entire county.

Using coyotes as bTB sentinels may not be appropriate in all regions. In a sentinel study at Riding Mountain National Park (RMNP) in Canada, Sangster et al. (2007) found no bTB infection in any coyotes sampled. While on the surface this may call into question the reliability of using coyotes, the ecology of study site must be understood as it is considerably different from that of Michigan's Lower Peninsula. The primary reservoir for bTB in RMNP is elk (Cervus elaphus manitobensis) whereas the primary diet of coyotes is deer (Paquet, 1992). Additionally, the presence of wolves (Canis lupus) at the Sangster et al. (2007) study site may influence coyotes' exposure to infected animals. While coyotes may scavenge elk carcasses killed by wolves, entrails are often consumed by wolves (Peterson and Ciucci, 2003), leaving little potential for disease transmission to coyotes. Thus, ecological factors must be taken into consideration when investigating the use of coyotes as sentinels for bTB. They may not be suitable for all environments.

\section{Conclusion}

This study demonstrates the use of coyotes as a surveillance tool to detect bTB in areas where bTB had not previously been detected. This is supported by not only the discovery of a bTB positive coyote in a previously uninfected county, but also the apparent lack of shedding of $M$. bovis by free-ranging bTB positive coyotes. The lack of bTB positive coyotes in Ogemaw and Kalkaska counties implies that bTB has not yet spread to these counties, but the re-emergence of bTB in Iosco County suggests the disease may be spreading out of its historic range. This is particularly important in the case of Cheboygan county, given its close proximity to currently or previously infected counties. Vigilance in surveillance must be maintained if progress toward eradication is to be maintained. Use of coyotes as sentinels to detect bTB spread in northeastern Michigan may be an effective tool toward this end.

\section{Conflict of interest statement}

The authors have not declared any conflict of interest.

\section{Acknowledgements}

The authors wish to thank T. Riley, R. Schanck and D. Lunning for assistance in the field, A. Aderman and P. 
Butchko from USDA Wildlife Services in Michigan for logistic and office support. Additional thanks to D. Kilpatrick and R. Pleszewski for aging the teeth and T. Atwood for helpful comments on an earlier draft of this paper. We are grateful to the Michigan Department of Agriculture and Department of Natural Resources for their support. Funding provided by USDA/APHIS/Veterinary Services.

\section{References}

Atwood, T.C., VerCauteren, K.C., DeLiberto, T.J., Smith, H.J., Stevenson, J.S. 2007. Coyotes as sentinels for monitoring bovine tuberculosis prevalence in white-tailed deer. J. Wildlife Manage 71, 1545-1554.

Andrews, R.D., Boggess, E.K., 2001. Ecology of coyotes in Iowa. In: Bekoff, M. (Ed.), Coyotes: Biology, Behavior, and Management. Blackburn Press, Caldwell, New Jersey, USA, pp. 249-265.

Bekoff, M., Gese, E.M., 2003. Coyote (Canis latrans). In: Feldhamer, G.A., Thompson, B.C., Chapman, J.A. (Eds.), Wild Mammals of North America: Biology, Management, and Conservation. 2nd ed. Johns Hopkins Press, Baltimore, Maryland, USA, pp. 467-481.

Bruning-Fann, C.S., Schmitt, S.M., Fitzgerald, S.D., Fierke, J.S., Friedrich, P.D., Kaneene, J.B., Clarke, K.A., Butler, K.L., Payeur, J.B., Whipple, D.L. Cooley, T.M., Miller, J.M., Muzo, D.P., 2001. Bovine tuberculosis in free-ranging carnivores from Michigan. J. Wildlife Dis. 37, 58-64.

Carbyn, L.N., Paquet, P.C., 1985. Long distance movement of a coyote from Riding Mountain National Park. J. Wildlife Manage. 50, 89.

Cheeseman, C.L., Wilesmith, J.W., Stuart, F.A., Mallinson, P.J., 1988 Dynamics of tuberculosis in a naturally infected badger population. Mamm. Rev. 18, 61-72.

Coleman, J.D., 1988. Distribution, prevalence, and epidemiology of bovine tuberculosis in brushtail possums, Trichosurus vulpecula, in the Hohonu Range, New Zealand. Aust. Wildlife Res. 15, 651-663.

Crossley, B.M., Zagmutt-Vergara, F.J., Fyock, T.L., Whitlock, R.H., Gardner, I.A., 2005. Fecal shedding of Mycobacterium avium subsp. paratuberculosis by dairy cows. Vet. Microbiol. 107, 257-263.

DeVos, V., Raath, J.P., Bengis, R.G., Kriek, N.J.P., Huchzermeyer, H., Keet, D.F., Michel, A., 2001. The epidemiology of tuberculosis in free ranging African buffalo (Syncerus caffer) in the Kruger National Park, South Africa. Onderstepoort J. Vet. 68, 119-130.

Dorn, M.L., Mertig, A.G., 2005. Bovine tuberculosis in Michigan: stakeholder attitudes and implications for eradication efforts. Wildlife Soc. B. 33, 539-552.

Eidson, M., Komar, N., Sorhage, F., Nelson, R., Talbot, T., Mostashari, F. McLean, R., 2001. Crow deaths as a sentinel surveillance system for West Nile Virus in the Northeastern United States, 1999. Emerg. Infect. Dis 7, 615-620.

Essey, M.A., Vantiem, J.S., 1995. Mycobacterium bovis infection in captive cervidae: an eradication program. In: Thoen, C.O., Steele, J.H (Eds.), Mycobacterium bovis Infection in Animals and Humans. Iowa State University Press, Ames, Iowa, USA, pp. 145-157.

Hines, N., Payeur, J.B., Hoffman, L.J., 2006. Comparison of the recovery of Mycobacterium bovis isolates using the BACTEC MGIT 960 system, BACTEC 460 system, and Middleborrk 7H10 and 7H11 solid media. J. Vet. Diagn. Invest. 18, 243-250.

Johnson, S.R., Dunbar, M.R., Martinez, L., Jones, R.L., Bowen, R., Gordy, P., 2008. Experimental inoculation of coyotes with Mycobacterium bovis: susceptibility and shedding. Proc. U.S. Animal Health Assoc. 112, 94-97.
Johnson, D.H., Joachim, D.G., Bachmann, P., Kardong, K.V., Stewart, R.E.A. Dix, L.M., Strickland, M.A., Watt, I.D., 1999. Aging furbearers using tooth structure and biomarkers. In: Wild Furbearer Management and Conservation in North America, Queen's Printer for Ontario, Canada, pp. 228-243.

Kolbe, J.A., Squires, J.R., 2004. Long distance movement by a coyote within the Rocky Mountains. Northwest Sci. 78, 344-345.

Lindenmayer, J.M., Marshall, D., Onderdonk, A.B., 1991. Dogs as sentinels for Lyme disease in Massachusetts. Am. J. Public Health 81, 1448-1455.

Milian-Suazo, F., Harris, B., Diza, C.A., Torres, C.R., Stuber, T., Ojeda, G.A., Loredo, A.M., Soria, M.P., Payeur, J.B., 2008. Molecular epidemiology of Mycobacterium bovis: usefulness in International trade. Prev. Vet. Med. 87, 261-271.

Munyeme, M., Muma, J.B., Samuui, K.L., Skjerve, E., Nambota, A.M., Phiri, I.G.K., Rigouts, L., Tryland, M., 2009. Prevalence of bovine tuberculosis and animal level risk factors for indigenous cattle under different grazing strategies in the livestock/wildlife interface areas of Zambia. Trop. Anim. Health Pro. 41, 345-352.

Nishi, J.S., Shury, T., Elkin, B.T., 2006. Wildlife reservoirs for bovine tuberculosis (Mycobacterium bovis) in Canada: Strategies for management and research. Vet. Microbiol. 112, 325-338.

Nugent, G., Whitford, J., Young, N., 2002. Use of released pigs as sentinels for Mycobacterium bovis. J. Wildlife Dis. 38, 665-677.

O'Brien, D. 2008. Bovine tb surveillance in free-ranging cervidae. 2007 Michigan Bovine TB Activities Report, p18.

O'Brien, D.J., Schmitt, S.M., Fierke, J.S., Hogle, S.A., Winterstein, S.R. Cooley, T.M., Moritz, W.E., Diegel, K.L., Fitzgerald, S.D., Berry, D.E. Kaneene, J.B., 2002. Epidemiology of Mycobacterium bovis in freeraging white tailed deer, Michigan, USA, 1995-2000. Prev. Vet. Med. 54, 47-63.

O’Brien, D.J., Schmitt, S.M., Fitzgerald, S.D., Berry, D.E., 2011. Management of bovine tuberculosis in Michigan wildlife: current status and near term prospects. Veterinary Microbiology 151, 179-187.

Ozoga, J.J., Harger, E.M., 1966. Winter activities and feeding habits of northern Michigan coyotes. J Wildlife Manage. 30, 809-818.

Paquet, P.C., 1992. Prey use strategies of sympatric wolves and coyotes in Riding Mountain National Park. Manitoba. J. Mammal. 73, 337 343.

Peterson, R.O., Ciucci, P., 2003. The wolf as a carnivore. In: Mech, L.D., Boitani, L. (Eds.), Wolves: Behavior, Ecology, and Conservation. The University of Chicago Press, pp. 104-130.

Sangster, C., Begeson, D., Lute-Wallace, C., Crichton, V., Wobeser, G., 2007. Feasibility of using coyotes (Canis latrans) as sentinels for bovine mycobacteriosis (Mycobacterium bovis) infection in wild cervids in and around Riding Mountain National Park, Manitoba. Canada. J. Wildlife Dis. 43, 432-438.

SAS Institute, 2004. SAS/STAT user's guide, version 9.1. SAS Institute, Cary, North Carolina, USA.

Schmitt, S.M., O’Brien, D.J., Hickling, G. 2006. Bovine tuberculosis annual report. 2006 Michigan Bovine TB Activities Report, 13-14.

Schmitt, S.M., O’Brien, D.J., Bruning-Fann, C.S., Fitzgerald, S.D., 2002. Bovine tuberculosis in Michigan wildlife and livestock. Ann. N.Y Acad. Sci. 969, 262-268.

Trainer, D.O., 1970. The use of wildlife to monitor zoonoses. J. Wildlife Dis. 6, 397-401.

United States Department of Agriculture NRCS National Cartography and Geospatial Center, 2007. http://datagateway.nrcs.usda.gov/GatewayHome.html (Accessed 18 March, 2009)

VerCauteren, K.C., Atwood, T.C., DeLiberto, T.J., Smith, H.J., Stevenson, J.S. Thomsen, B.V., Gidlewski, T., Payeur, J., 2008. Sentinel-based surveillance of coyotes to detect bovine tuberculosis. Michigan. Emerg. Infect. Dis. 14, 1862-1869. 